\title{
Anionic Ring-Opening Polymerization of 1,2,2-Trimethyl-1-phenyl-1,2-disilacyclopentane
}

\author{
Masato Suzuki, ${ }^{\dagger, *}{ }^{\dagger \dagger}$ Tomomasa KaneKo, ${ }^{*}$ Yoshiyuki Morishima, ${ }^{* *}$ Tatsuhiko ObaYashi, ${ }^{* *}$ \\ and Takeo SAEGUSA**,+† \\ * Division of Polymer Chemistry, Graduate School of Engineering, Kyoto University, Kyoto 606-01, Japan \\ ** Department of Synthetic Chemistry, Faculty of Engineering, Kyoto University, Kyoto 606-01, Japan
}

(Received August 9, 1995)

\begin{abstract}
The anionic ring-opening polymerization of 1,2,2-trimethyl-1-phenyl-1,2-disilacyclopentane took place in THF at $0 \sim-78^{\circ} \mathrm{C}$. The initiators were ${ }^{n} \mathrm{Bu}_{4} \mathrm{NF}, \mathrm{PhMe}_{2} \mathrm{SiK}$, and $\left(\mathrm{PhMe}_{2} \mathrm{Si}\right)_{2} \mathrm{Cu}(\mathrm{CN}) \mathrm{Li}_{2}$. When $\mathrm{PhMe}{ }_{2} \mathrm{SiK}$ was used, the addition of HMPA was required for the polymerization. The polymerization initiated with $\left(\mathrm{PhMe}_{2} \mathrm{Si}\right)_{2} \mathrm{Cu}(\mathrm{CN}) \mathrm{Li}{ }_{2}$ showed a living character to some extent. The product polymers contained not only a head-to-tail structure but also head-to-head and tail-to-tail structures, whose amounts were dependent on the initiator: $4 \%\left({ }^{n} \mathrm{Bu}_{4} \mathrm{NF}\right), 30 \%\left(\mathrm{PhMe}{ }_{2} \mathrm{SiK}\right)$, and $12 \%$ $\left(\left(\mathrm{PhMe}_{2} \mathrm{Si}\right)_{2} \mathrm{Cu}(\mathrm{CN}) \mathrm{Li}_{2}\right)$. These values reflect the efficiency of the phenyl group to stabilize the silyl anion that is the propagating end.

KEY WORDS Anionic Polymerization / Ring-Opening Polymerization / Disilacyclopentane / Silicon-Containing Polymer/Silyl Cuprate /
\end{abstract}

It is of much interest that an $\mathrm{Si}-\mathrm{Si} \sigma$ bond has analogous character and reactivity with a $\mathrm{C}=\mathrm{C} \pi$ bond, e.g., $\sigma-\sigma$ or $\sigma-\pi$ conjugation, coordination to transition metals, and $\mathrm{C}-\mathrm{T}$ complex formation. ${ }^{1}$ This analogy, linking with the fact that polymerization of a $\mathrm{C}=\mathrm{C} \pi$ bond is the biggest and most basic field in polymerization chemistry, prompted us to study polymerization participated with an $\mathrm{Si}-\mathrm{Si} \sigma$ bond. It is inevitably designed as ring-opening polymerization that proceeds through scission-recombination of $\mathrm{Si}-\mathrm{Si} \sigma$ bonds (Scheme 1). The propagating end is accordingly a silicon active species, as is interestingly compared with the ordinary vinyl polymerization conducted by a carbon active species.

In this context, we have already found the anionic ring-opening polymerization of 1,1,2,2-tetramethyl-1,2disilacyclopentane and -hexane. ${ }^{2}$ It is then interesting to investigate a substituent effect on this polymerization. We here describe the anionic ring-opening polymerization of 1,2,2-trimethyl-1-phenyl-1,2-disilacyclopentane (1) (Scheme 2). A phenyl group is capable of conjugating with an $\mathrm{Si}-\mathrm{Si}$ bond and stabilizing a silyl anion that



Scheme 1

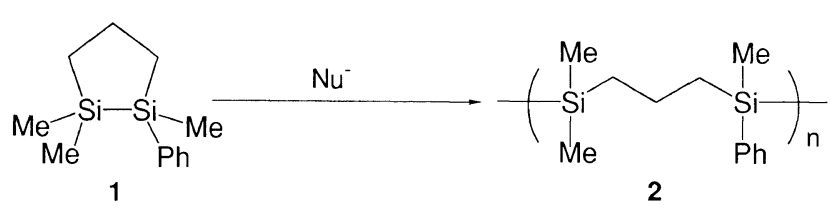

Scheme 2 is the propagating end, however, weakly as compared with these effects on a $\mathrm{C}=\mathrm{C} \pi$ bond and a carbon anion. ${ }^{1}$ By introducing a phenyl group on a silicon atom, we recently succeeded in regio-selective ring scission of cyclopentasilane leading to the production of the sequence ordered polysilane by way of anionic ringopening polymerization. ${ }^{3}$ This paper presents further information on the substituent effects of the phenyl group, discussing the anionic ring-opening polymerization of 1. In addition, a higher ordered silylcuprate is introduced as a new initiator.

Before mentioning the results, we have to refer to the related studies. Polymerizations of cyclic carbosilanes such as silacyclobutane and 1,3-disilacyclobutane were found more than thirty years ago. Recently, increasing interest in Si-containing polymers as new materials has promoted reinvestigation of this field, including studies about several new types of monomers. ${ }^{4,5}$ There thus appeared polymerizations of cyclic systems containing an $\mathrm{Si}-\mathrm{Si}$ bond(s): the thermal or $\mathrm{AlCl}_{3}$-catalyzed polymerization of benzo-1,2-disilacyclobutene, ${ }^{6}$ the anionic polymerization of 1,2,3,4-tetramethyl-1,2,3,4-tetraphenylcyclotetrasilane, ${ }^{7}$ the anionic polymerizations of 1-phenyl-7,8-disilabicyclo[2.2.2] octa-2,5-dienes, ${ }^{8}$ and the anionic, thermal, or radical polymerizations of 1,2,5,6-tetrasilacycloocta-3,7-diynes. ${ }^{9}$ The former two include the scission-recombination process of the $\mathrm{Si}-\mathrm{Si}$ bond. The second polymerization, published during our study, apparently propagates by the reaction of an $\mathrm{Si}-$ $\mathrm{Si}$ bond with a silyl anion. From a larger viewpoint on the basis of the above-mentioned conception, we have advanced our studies. It should be mentioned that palladium-catalyzed copolymerizations of cyclopolysilanes and cyclic disilanes with $p$-quinones were recently reported. ${ }^{10}$

\footnotetext{
† To whom correspondences should be addressed.

${ }^{\dagger}$ Present address: Research Laboratory of Resources Utilization, Tokyo Institute of Technology, 4259 Nagatsuta-cho, Midori-ku, Yokohama 226, Japan.

${ }^{\dagger \dagger}$ Present address: Kansai Research Institute, Kyoto Research Park, 17 Chudoji Minami-Machi, Shimogyo-ku, Kyoto 600, Japan.
} 


\section{EXPERIMENTAL}

Diethyl ether and tetrahydrofuran (THF) were dried over $\mathrm{Na}$ and freshly distilled under Ar before use. Hexane and toluene were dried over $\mathrm{Na}$, distilled, and stored under $\mathrm{N}_{2}$. hexamethylphosphoramide (HMPA) and acetonitrile dried over $\mathrm{CaH}_{2}$ were distilled under $\mathrm{Ar}$ and stored over molecular sieves 3A (Merck). Other commercially available reagents were used without further purification unless otherwise noted.

GPC analysis was carried out by use of Shodex ${ }^{\circledR} \mathrm{K}-803$ and $\mathrm{K}-802$ (Showa Denko) as the column and $\mathrm{CHCl}_{3}$ as the eluent. The GPC calibration curves were made on the basis of polystyrene standards. VPO measurement was carried out in $\mathrm{CHCl}_{3}$ at $40^{\circ} \mathrm{C}$.

NMR measurement on the course of monomer synthesis was performed using HITACHI R-600 $(60 \mathrm{MHz}$ for $\left.{ }^{1} \mathrm{H}\right)$ and $\mathrm{R}-900\left(90 \mathrm{MHz}\right.$ for $\left.{ }^{1} \mathrm{H}\right)$ spectrometers. NMR spectra of the polymers were recorded on a JOEL JMX-JX-400 spectrometer $\left(400 \mathrm{MHz}\right.$ for $\left.{ }^{1} \mathrm{H}\right)$.

\section{Monomer Synthesis}

The monomer, 1,2,2-trimethyl-1-phenyl-1,2-disilacyclopentane (1), was prepared according to the following three steps under $\mathrm{N}_{2}$ (Scheme 3).

(1) To a solution of dichloro(methyl)(phenyl)silane $(10 \mathrm{~g}, 52 \mathrm{mmol})$ in diethyl ether $(50 \mathrm{ml})$ was slowly added allylmagnesium chloride ${ }^{11}(0.48 \mathrm{M}$ in diethyl ether, $109 \mathrm{ml}, 52 \mathrm{mmol}$ ) at $-78^{\circ} \mathrm{C}$ over $1 \mathrm{~h}$. After stirring for $2 \mathrm{~h}$, the reaction mixture was allowed to warm to ambient temperature. $\mathrm{MgCl}_{2}$ precipitated was filtered off under $\mathrm{N}_{2}$ and the filtrate was concentrated under reduced pressure. The residue was distilled to give allyl(chloro)(methyl)(phenyl)silane $\left(7.8 \mathrm{~g}, 76 \%\right.$ ): bp $56-57^{\circ} \mathrm{C} / 1.2$ $\mathrm{mmHg} ;{ }^{1} \mathrm{H}$ NMR $\left(\mathrm{CDCl}_{3}\right) \delta 0.57(\mathrm{~s}, 3 \mathrm{H}), 1.78(\mathrm{dd}, J=$ $7.6 \mathrm{~Hz}, J=12.0 \mathrm{~Hz}, 2 \mathrm{H}), 4.45-5.05(\mathrm{~m}, 2 \mathrm{H}), 5.21-$ $6.05(\mathrm{~m}, 1 \mathrm{H}), 6.87-7.81(\mathrm{~m}, 5 \mathrm{H})$.

(2) To a solution of chloro(dimethyl)silane $(7.0 \mathrm{~g}$, $75 \mathrm{mmol})$ in toluene $(100 \mathrm{ml})$ containing a catalytic amount of $\mathrm{H}_{2} \mathrm{PtCl}_{6} \cdot 6 \mathrm{H}_{2} \mathrm{O}$ was added allyl(chloro)(methyl)(phenyl)silane $(10 \mathrm{~g}, 51 \mathrm{mmol})$ over $30 \mathrm{~min}$. The addition should be controlled because moderate heat evolution was observed after an induction period (a few minutes). After the exothermic reaction ceased, the reaction mixture was heated to reflux for $30 \mathrm{~min}$. The solvent was then excluded under reduced pressure and the residue was distilled to give 2,6-dichloro-6-methyl-2phenyl-2,6-disilaheptane $(12.5 \mathrm{~g}, 84 \%)$ : bp $105-110^{\circ} \mathrm{C} /$ $0.5 \mathrm{mmHg} ;{ }^{1} \mathrm{H}$ NMR $\left(\mathrm{CDCl}_{3}\right) \delta 0.23(\mathrm{~s}, 6 \mathrm{H}), 0.57(\mathrm{~s}$, $3 \mathrm{H}), 0.68-1.85(\mathrm{~m}, 6 \mathrm{H}), 7.06-7.74(\mathrm{~m}, 5 \mathrm{H})$.

(3) Lithium metal ( $0.65 \mathrm{~g}, 95 \mathrm{mg}$ atom) (lithium oxide on the surface should be excluded as much as possible) was cut into small pieces and simultaneously dropped into THF $(120 \mathrm{ml})$. To the mixture cooled to $0^{\circ} \mathrm{C}$ was slowly added 2,6-dichloro-6-methyl-2-phenyl-2,6-disilaheptane $(13.0 \mathrm{~g}, 45 \mathrm{mmol})$ in THF $(15 \mathrm{ml})$ over $1 \mathrm{~h}$ with vigorous stir. After $2.5 \mathrm{~h}$ at $0^{\circ} \mathrm{C}$, THF was evaporat- ed from the reaction mixture under reduced pressure. Hexane $(100 \mathrm{ml})$ was added to the residue and the precipitated material was filtrated off under $\mathrm{N}_{2}$. To the filtrate was added a diethyl ether solution of methyl lithium $(1.0 \mathrm{M}, 28 \mathrm{ml}, 28 \mathrm{mmol})$ at $0^{\circ} \mathrm{C}$. After disappearance of the siloxane (by-product) was confirmed by gas chromatography (after $2 \mathrm{~h}$ ), excess of iodomethane was added to neutralize the mixture; when the siloxane still remained, methyl lithium was added and the reaction was continued. The precipitate, lithium iodide, was filtrated off under $\mathrm{N}_{2}$, and the filtrate was subjected to the distillation under reduced pressure to give 1,2,2trimethyl-1-phenyl-1,2-disilacyclopentane $(3.2 \mathrm{~g}, 31 \%)$ : bp $72-75^{\circ} \mathrm{C} / 0.8 \mathrm{mmHg}$ (lit. ${ }^{12}: 105^{\circ} \mathrm{C} / 2.5 \mathrm{mmHg}$ ); ${ }^{1} \mathrm{H}$ $\operatorname{NMR}\left(\mathrm{CDCl}_{3}\right) \delta 0.12(\mathrm{~s}, 3 \mathrm{H}), 0.21(\mathrm{~s}, 3 \mathrm{H}), 0.40(\mathrm{~s}, 3 \mathrm{H})$, $0.65-1.12(\mathrm{~m}, 4 \mathrm{H}), 1.64-2.01(\mathrm{~m}, 2 \mathrm{H}), 7.31-7.62(\mathrm{~m}$, $5 \mathrm{H}) ;{ }^{13} \mathrm{C}$ NMR $\left(\mathrm{CDCl}_{3}\right) \delta-4.38,-3.00,-2.65$, $18.87,19.91,23.72,127.48,128.17,134.07,138.89$.

\section{Polymerization with ${ }^{n} \mathrm{Bu}_{4} \mathrm{NF}$}

According to the literature, ${ }^{13}$ commercially available ${ }^{n} \mathrm{Bu}_{4} \mathrm{NF}$ hydrate was azeotropically dried twice with benzene-acetonitrile $(3: 1, \mathrm{v} / \mathrm{v})$ under reduced pressure and kept in vacuo for $12 \mathrm{~h}$. THF was then added to the residue. The concentration of ${ }^{n} \mathrm{Bu}_{4} \mathrm{NF}$ was determined by relative weight content.

To $1(220 \mathrm{mg}, 1 \mathrm{mmol})$ in THF $(1 \mathrm{ml})$ was added THF solution of ${ }^{n} \mathrm{Bu}_{4} \mathrm{NF}(0.02 \mathrm{mmol})$ under $\mathrm{Ar}$ at the temperature shown in Table I. The conversion of $\mathbf{1}$ was monitored by gas chromatography. After 1 was almost consumed, excess MeI $(50 \mu \mathrm{l})$ for the initiator was added to the reaction mixture. Pouring this mixture into $\mathrm{MeOH}$ precipitated the paste-like polymer: ${ }^{1} \mathrm{H}$ NMR $\left(\mathrm{CD}_{2} \mathrm{Cl}_{2}\right.$, Figure 1) $\delta-0.02(\mathrm{~s}, 6 \mathrm{H}), 0.24(\mathrm{~s}, 3 \mathrm{H}), 0.61(\mathrm{t}, J=$ $8.2 \mathrm{~Hz}, 2 \mathrm{H}), 0.84(\mathrm{t}, J=7.9 \mathrm{~Hz}, 2 \mathrm{H}), 1.29(\mathrm{~m}, 2 \mathrm{H}), 7.26$ $(\mathrm{m}, 3 \mathrm{H}), 7.35(\mathrm{~m}, 2 \mathrm{H}) ;{ }^{13} \mathrm{C}$ NMR $\left(\mathrm{CD}_{2} \mathrm{Cl}_{2}\right.$, Figure 2$) \delta$ $-5.74,-5.73,-3.43,-3.41,19.06,19.07,20.18,20.52$, $128.09,128.58,134.46,139.28 ;{ }^{29} \mathrm{Si} \mathrm{NMR}\left(\mathrm{CDCl}_{3}, \mathrm{ppm}\right.$, Figure 3) - 20.80, - 18.57; Anal. Calcd: C 65.38, H 9.14, Found: $\mathrm{C}$ 64.46, $\mathrm{H}$ 9.16: a little error in the $\mathrm{C}$ content is assumably due to ceramization.

\section{Polymerization with $\mathrm{PhMe}_{2} \mathrm{SiK}$}

A THF solution of $\mathrm{PhMe}_{2} \mathrm{SiK}$ was prepared as follows. To potassium metal $(150 \mathrm{mg}, 3.84 \mathrm{mg}$ atom $)$ in THF $(5 \mathrm{ml})$ was added 1,1,2,2-tetramethyl-1,2-diphenyldisilane $(500 \mathrm{mg}, 1.85 \mathrm{mmol})$. The mixture was stirred for $5 \mathrm{~h}$ at room temperature under Ar. The concentration of $\mathrm{PhMe}_{2} \mathrm{SiK}$, evaluated by titration with $0.01 \mathrm{M} \mathrm{HCl} \mathrm{aq,}$ was $0.600 \mathrm{mmol} \mathrm{g}^{-1}$ solution.

The procedure for the polymerization of 1 using $\mathrm{PhMe}_{2} \mathrm{SiK}$ was the same as that using ${ }^{n} \mathrm{Bu}_{4} \mathrm{NF}$ with the exception that HMPA $(50 \mu \mathrm{l})$ was added to the reaction media.

\section{Polymerization with $\left(\mathrm{PhMe}_{2} \mathrm{Si}_{2} \mathrm{Cu}(\mathrm{CN}) \mathrm{Li}_{2}\right.$}

According to the literature, ${ }^{14}\left(\mathrm{PhMe}_{2} \mathrm{Si}\right)_{2} \mathrm{Cu}(\mathrm{CN}) \mathrm{Li}_{2}$

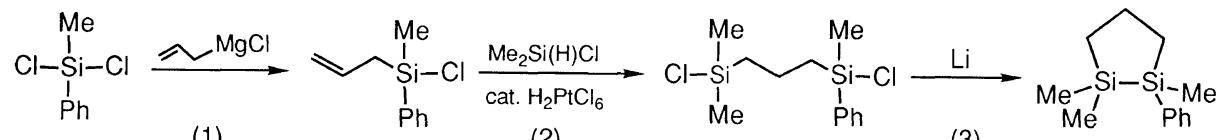

(1)
(3) 
was prepared just before use by reaction of $\mathrm{PhMe}_{2} \mathrm{SiLi}$ with a homogenous solution of $\mathrm{CuCN}$ with $\mathrm{LiCl}$ in THF. The preparation of $\mathrm{PhMe}_{2} \mathrm{SiLi}$ was carried out in a similar way to that of $\mathrm{PhMe}_{2} \mathrm{SiK}$. Stirring 1,1,2,2tetramethyl-1,2-diphenyldisilane $(1.35 \mathrm{~g}, 5 \mathrm{mmol})$ with lithium metal $(70 \mathrm{mg}, 10 \mathrm{mg}$ atom) in THF $(25 \mathrm{ml})$ at $-10^{\circ} \mathrm{C}$ for $36 \mathrm{~h}$ produced a THF solution of $\mathrm{PhMe}_{2} \mathrm{SiLi}$ whose concentration was $0.417 \mathrm{mmol} \mathrm{g}^{-1}$ solution. $\mathrm{CuCN}$ purchased from Mitsuwa Chemicals was azeotropically dried with toluene under reduced pressure three times, and $\mathrm{LiCl}$ was dried over a flame in vacuo. $\mathrm{CuCN}$ was mixed with 2 eq of $\mathrm{LiCl}$ in THF to give a homogenous solution. The concentration was evaluated by relative weight content.

The polymerization of 1 was carried out under Ar at the temperature shown in Table II. The THF solutions of $\mathrm{CuCN} \cdot 2 \mathrm{LiCl}(0.2 \mathrm{mmol})$ and $\mathrm{PhMe}_{2} \mathrm{SiLi}(0.4 \mathrm{mmol})$ were mixed in THF $(10 \mathrm{ml})$ containing $n$-decane $(1 \mathrm{mmol})$ as the internal standard for gas chromatographical analysis. After $1 \mathrm{~h}, \mathbf{1}(10 \mathrm{mmol})$ was added to the reaction mixture, and conversion was monitored. The addition of MeI $(200 \mu \mathrm{l})$ was followed by gradually warming the mixture to ambient temperature. The precipitate obtained by pouring the reaction mixture into $\mathrm{MeOH}$ was resolved in $\mathrm{CH}_{2} \mathrm{Cl}_{2}$. The solution was washed with dil $\mathrm{NH}_{3}$ aq to extract copper and dried over $\mathrm{MgSO}_{4}$. Evaporating $\mathrm{CH}_{2} \mathrm{Cl}_{2}$ under reduced pressure gave the pure polymer.

\section{RESULTS AND DISCUSSION}

\section{Monomer Synthesis}

The monomer, 1,2,2-trimethyl-1-phenyl-1,2-disilacyclopentane (1), was synthesized in 1964. ${ }^{12}$ However, we applied the method for the preparation of 1,1,2,2tetramethyl-1,2-disilacyclopentane $(3)^{2}$ to prepare 1 (Scheme 3). In the final step, however, HMPA whose addition was required for the production of $\mathbf{3}$ was unnecessary for 1. This agrees with the fact that dimethylphenylsilyl lithium is generated in THF without HMPA but trimethylsilyl lithium is not. ${ }^{1}$ As generally observed in a coupling reaction of chlorosilane with alkali metal, monomer 1 produced in the final step was also contaminated with the siloxane, i.e., 2,6,6-trimethyl-2phenyl-1-oxa-2,6-disilacyclohexane, whose chromatographical separation was difficult. Washing with cold concd $\mathrm{H}_{2} \mathrm{SO}_{4}$ is usually effective to eliminate siloxane. ${ }^{15}$ But this method was not applicable because 1 was easily decomposed by concd $\mathrm{H}_{2} \mathrm{SO}_{4}$. We thus explored a good method to eliminate the contaminant and successfully found treatment with methyl lithium in hexane-ether to be effective to liberate 1 from the contamination with the siloxane.

\section{Polymerization}

Initiators such as ${ }^{n} \mathrm{Bu}_{4} \mathrm{NF}, \mathrm{PhMe}_{2} \mathrm{SiK}$, and $\left(\mathrm{PhMe}_{2}-\right.$ $\mathrm{Si})_{2} \mathrm{Cu}(\mathrm{CN}) \mathrm{Li}_{2}$ were used for the anionic ring-opening polymerization of $\mathbf{1}$. The results are discussed comparatively about each initiator in the following sections.

\section{Initiated with ${ }^{n} \mathrm{Bu}_{4} \mathrm{NF}$}

Owing to the Si-affinity of fluoride anion, ${ }^{n} \mathrm{Bu}_{4} \mathrm{NF}$ is capable of initiating the polymerization of $\mathbf{1}$ by the
Table I. Anionic ring-opening polymerization of 1,2,2-trimethyl-1-phenyl-1,2-disilacyclopentane (1)

\begin{tabular}{|c|c|c|c|c|c|c|c|}
\hline Run & Initiator $^{\mathbf{a}}$ & Solvent & $\frac{\text { Temp }}{{ }^{\circ} \mathrm{C}}$ & $\frac{\text { Time }}{\mathrm{h}}$ & $\frac{\text { Yield }^{\mathrm{b}}}{\%}$ & $M_{n}^{\mathrm{c}}$ & $M_{w} / M_{n}$ \\
\hline 1 & ${ }^{n} \mathrm{Bu}_{4} \mathrm{NF}$ & THF & 0 & 4 & 72 & 6400 & 2.09 \\
\hline 2 & ${ }^{n} \mathrm{Bu}_{4} \mathrm{NF}$ & THF & -50 & 1 & 97 & 9300 & 2.17 \\
\hline 3 & $\mathrm{PhMe}_{2} \mathrm{SiK}$ & THF/HMPA ${ }^{\mathrm{d}}$ & 0 & 4.5 & 78 & 6000 & 1.91 \\
\hline 4 & $\mathrm{PhMe}_{2} \mathrm{SiK}$ & THF/HMPA ${ }^{\mathrm{d}}$ & -40 & 6 & 91 & 19000 & 2.22 \\
\hline
\end{tabular}

a $2 \mathrm{~mol} \%$ for 1. b Coversion of $1>90 \%$, yield $=\mathrm{wt}^{\mathrm{t}} \%$ of a $\mathrm{MeOH}$-insoluble part. ${ }^{\mathrm{c}}$ Estimated by GPC (PSt standard: eluent, $\left.\mathrm{CHCl}_{3}\right) .{ }^{\mathrm{d}} \mathrm{THF}-\mathrm{HMPA}=20: 1(\mathrm{v} / \mathrm{v})$.

reaction with the $\mathrm{Si}-\mathrm{Si}$ bond to generate the metal-free silyl anion. The polymerization smoothly took place in THF (runs 1 and 2 in Table I) in contrast with the polymerization of 3 requiring the addition of HMPA. ${ }^{2}$ It is evident that this difference arises from the anion stabilization effect of the phenyl group. The reaction mixtures of both of these two runs showed two elution peaks on the GPC charts; they were ascribable to the polymer and the oligomer, respectively. This finding indicates that the polymerization under above conditions includes some side reactions such as back-biting and chain-transfer. The polymer was isolated by the precipitation into $\mathrm{MeOH}$.

The structure of the product polymer was investigated in detail by NMR spectroscopy. Figures 1, 2, and 3 respectively shows the ${ }^{1} \mathrm{H},{ }^{13} \mathrm{C}$, and ${ }^{29} \mathrm{Si} \mathrm{NMR}$ spectra of the polymer produced at $0^{\circ} \mathrm{C}$ (run 1). These spectra suggest the fairly regular structure of the polymer shown as 2 . The ${ }^{29} \mathrm{Si}$ NMR spectrum (Figure 3 ), showing two peaks except for a trace of peaks, informs that two kinds of silicon atoms almost exclusively construct the polymer; these peaks were easily assigned on the basis of the chemical shift values (a trace of an irregular structure is discussed in the next section). The peak assignment in the ${ }^{1} \mathrm{H}$ NMR spectrum (Figure 1) was confirmed by the ${ }^{1} \mathrm{H}$ NOESY $2 \mathrm{D}$ NMR spectrum. Then, the peaks in the ${ }^{13} \mathrm{C}$ NMR spectrum (Figure 2) have been assigned with the aid of ${ }^{1} \mathrm{H}-{ }^{13} \mathrm{C}$ COSY 2D NMR spectrum. It is noted that there are observed clearly separate two peaks for the carbons $E$ and very close two peaks for the carbons $\mathrm{A}$ and $\mathrm{B}$ respectively. The two methyl carbons labeled $E$ are essentially different in NMR spectroscopy due to the vicinal substituents so that the above observation is reasonable for the carbons $\mathrm{E}$. As for the carbons $\mathrm{A}$ and $\mathrm{B}, \zeta$-tacticity has to be considered to explain the peak separation. Theoretically, the carbon A should have shown three peaks due to triad. It seems that they are not completely discriminated from each other. On the other hand, it is reasonable that the diad causes the peak for the carbon B to separate into two.

\section{Initiated with $\mathrm{PhMe}_{2} \mathrm{SiK}$}

When $\mathrm{PhMe}_{2} \mathrm{SiK}$ was used as the initiator, the addition of a small amount of HMPA (THF : HMPA $=20: 1, \mathrm{v} / \mathrm{v}$ ) was required for the polymerization of 1 (runs 3 and 4 in Table I). The effect of HMPA is to activate the silyl anion by coordination to potassium cation. In contrast with the polymerization initiated with ${ }^{n} \mathrm{Bu}_{4} \mathrm{NF}$, GPC analysis of these reaction mixtures showed no noticeable 


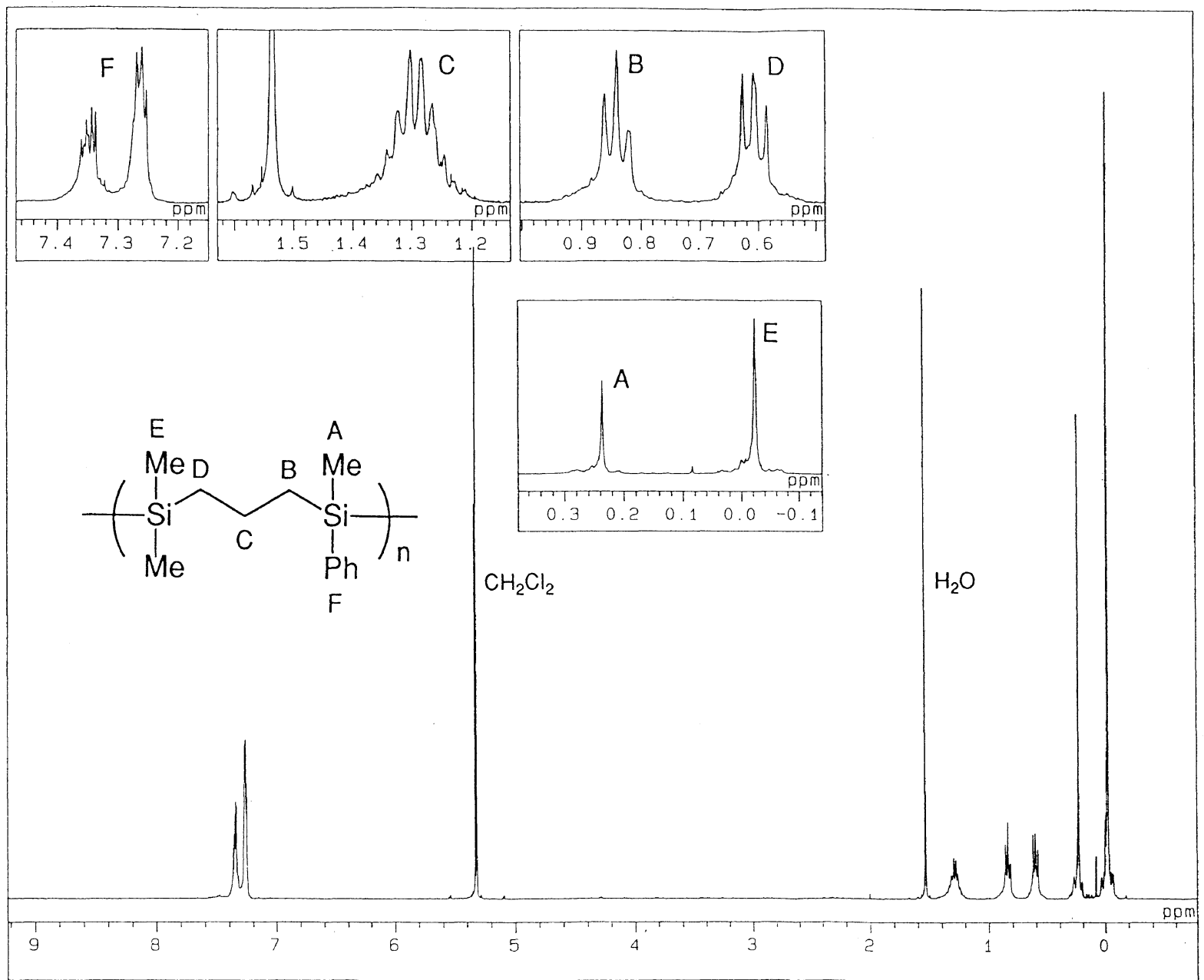

Figure 1. ${ }^{1} \mathrm{H}$ NMR spectrum (in $\mathrm{CD}_{2} \mathrm{Cl}_{2}$ ) of the polymer produced with ${ }^{n} \mathrm{Bu}_{4} \mathrm{NF}$ (run 1 in Table I).

peak due to the oligomer. This means that the back-biting reaction hardly occurred during the polymerization. The higher molecular weight polymer was obtained at the lower reaction temperature that suppressed the chaintransfer reaction, but its molecular weight distribution was still over 2 .

The product polymers showed very different NMR spectra from that produced with ${ }^{n} \mathrm{Bu}_{4} \mathrm{NF}$. The NMR spectra of the polymer produced at $-40^{\circ} \mathrm{C}$ (run 4) was analyzed in detail. In the ${ }^{29} \mathrm{Si}$ NMR spectrum (Figure 4), there were observed two pairs of the bigger and the smaller peaks. This chart informs that the polymer consists of not only the $\mathrm{H}-\mathrm{T}$ (head to tail) but also the $\mathrm{H}-\mathrm{H}$ and $\mathrm{T}-\mathrm{T}$ connections. A couple of the smaller peaks at -18.75 and $-21.17 \mathrm{ppm}$ are assignable to the silicons of the $\mathrm{T}-\mathrm{T}$ and $\mathrm{H}-\mathrm{H}$ connections, respectively. The proportion of the $\mathrm{H}-\mathrm{H}(\mathrm{T}-\mathrm{T})$ to the $\mathrm{H}-\mathrm{T}$ connection was easily calculated to be $\mathrm{H}-\mathrm{T}: \mathrm{H}-\mathrm{H}(\mathrm{T}-\mathrm{T})=0.70: 0.15$ on the basis of the integral ratio of the corresponding peaks.

The ${ }^{1} \mathrm{H}$ and ${ }^{13} \mathrm{C}$ NMR spectra are rather complicated (Figures 5 and 6). The clue to analyze the structure is obtained only from the peaks due to the carbon $\mathrm{C}$ in the ${ }^{13} \mathrm{C}$ NMR spectra. It is noticed on the expanded chart of the corresponding part that there are observed two smaller peaks having equal intensity on the both sides of one bigger peak. All of them are assignable to the carbon C. As shown in Scheme 4, there are four

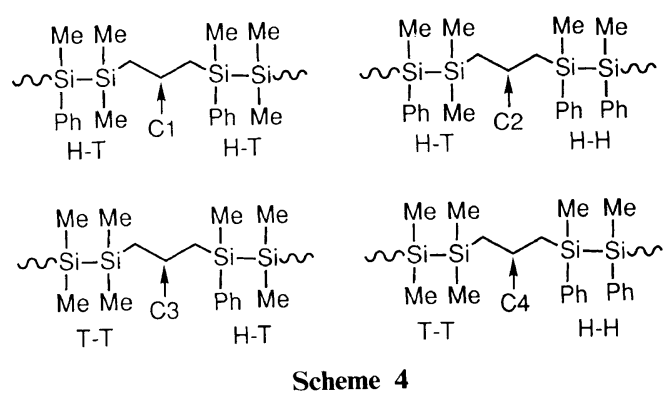

kinds of the carbon $\mathrm{C}$ due to the $\mathrm{H}-\mathrm{T}$ connectivities. Considering the environment around the carbon $\mathrm{C}$, the three peaks are reasonably assigned as follows; the central peak is due to not only the carbon $\mathrm{Cl}$ but also the carbon $\mathrm{C} 4$, and the other two are due to the carbons $\mathrm{C} 2$ and C3. Thus, from the integral ratio $(=0.410)$ of one of the latter peaks to the former, the relative content $(=\mathrm{X})$ of the $\mathrm{H}-\mathrm{H}(\mathrm{T}-\mathrm{T})$ connection can be calculated according to the equation: $2 \mathrm{X}(1-2 \mathrm{X}) /\left\{\mathrm{X}^{2}+(1-2 \mathrm{X})^{2}\right\}=0.410$. As the result, the evaluated value of the ratio $\mathrm{H}-\mathrm{T}: \mathrm{H}-$ $\mathrm{H}(\mathrm{T}-\mathrm{T})(=(1-2 \mathrm{X}): \mathrm{X})$ was $0.70: 0.15$, the same as that calculated on the basis of the data in the ${ }^{29} \mathrm{Si} \mathrm{NMR}$ spectrum. When careful attention is paid again to the same part of the ${ }^{13} \mathrm{C}$ NMR spectrum of the polymer produced with $\mathrm{Bu}_{4} \mathrm{NF}$ (Figure 2), two tiny peaks are noticed to imply the existence of a trace amount of the $\mathrm{H}-\mathrm{H}$ and $\mathrm{T}-\mathrm{T}$ structures. The ratio $\mathrm{H}-\mathrm{T}: \mathrm{H}-\mathrm{H}(\mathrm{T}-\mathrm{T})$ was 


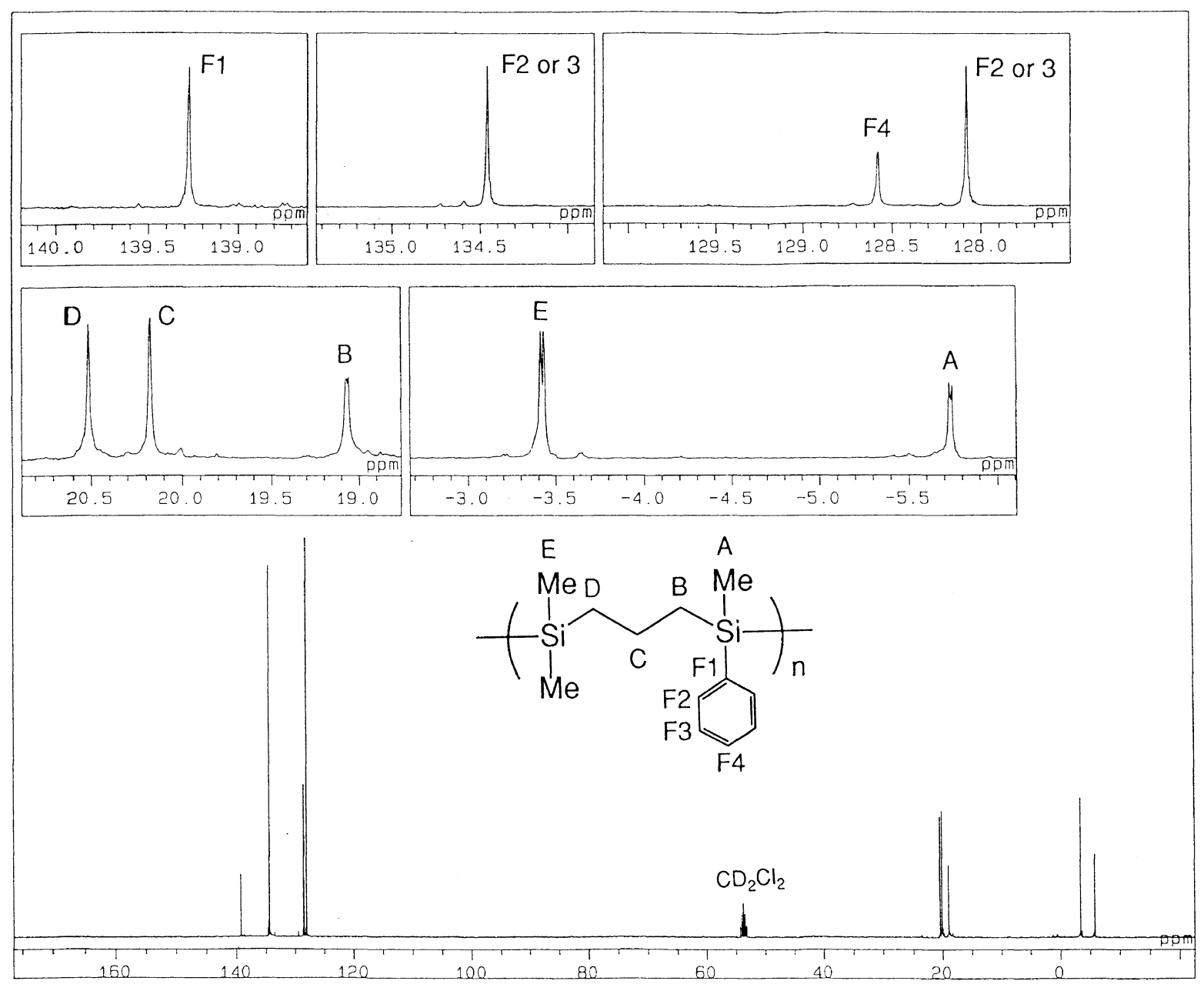

Figure 2. ${ }^{13} \mathrm{C}$ NMR spectrum $\left({ }^{1} \mathrm{H}\right.$ complete decoupling, in $\mathrm{CD}_{2} \mathrm{Cl}_{2}$ ) of the polymer produced with ${ }^{n} \mathrm{Bu}_{4} \mathrm{NF}$ (run 1 in Table I).

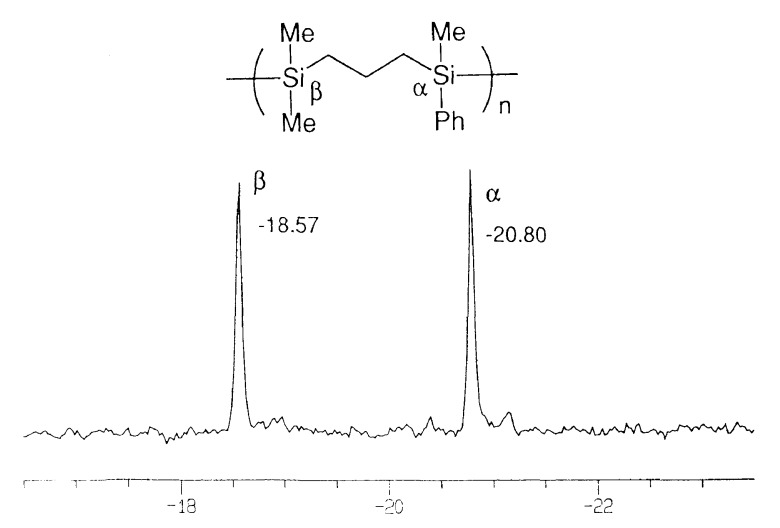

Figure 3. ${ }^{29} \mathrm{Si} \mathrm{NMR}$ spectrum $\left({ }^{1} \mathrm{H}\right.$ gate decoupling, in $\left.\mathrm{CDCl}_{3}\right)$ of the polymer produced with ${ }^{n} \mathrm{Bu}_{4} \mathrm{NF}$ (run 1 in Table I).

calculated as $0.96: 0.02$.

Formation of the $\mathrm{H}-\mathrm{H}$ and $\mathrm{T}-\mathrm{T}$ structures means that not only the alkyl(methyl)(phenyl)silyl anion but also the alkyl(dimethyl)silyl anion is generated as the propagating end. Although the silyl anion is certainly stabilized by the introduction of phenyl in place of methyl on the silicon atom, its efficiency is dependent on a solvent, an additive, and a counter cation. When the silyl anion coupled with potassium cation is compared with a non-metallic silyl anion generated with ${ }^{n} \mathrm{Bu}_{4} \mathrm{NF}$, the former is in a more stable state than the latter.
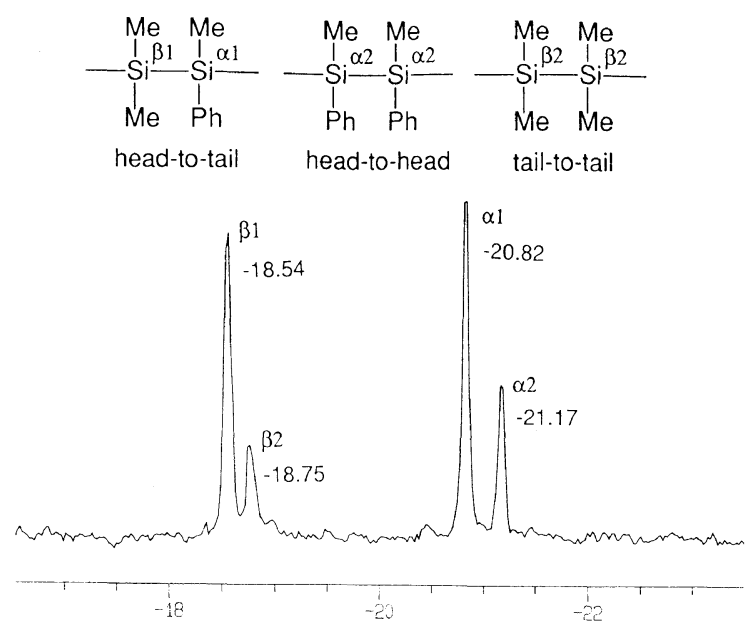

Figure 4. ${ }^{29} \mathrm{Si} \mathrm{NMR} \mathrm{spectrum}\left({ }^{1} \mathrm{H}\right.$ gate decoupling, in $\left.\mathrm{CDCl}_{3}\right)$ of the polymer produced with $\mathrm{Me}_{3} \mathrm{SiK}$ (run 4 in Table I).

Accordingly, it seems that the stabilization effect of the phenyl group is less efficient in the case of the former. This may be a reasonable explanation for the observation that the polymer produced with $\mathrm{PhMe}_{2} \mathrm{SiK}$ contained more $\mathrm{H}-\mathrm{H}$ and $\mathrm{T}-\mathrm{T}$ structures.

Initiated with $\left(\mathrm{PhMe}_{2} \mathrm{Si}\right)_{2} \mathrm{Cu}(\mathrm{CN}) \mathrm{Li}_{2}$

Although cuprate is usually derived from $\mathrm{RLi}$ or $\mathrm{RMgX}$, the reaction feature of the former is much 


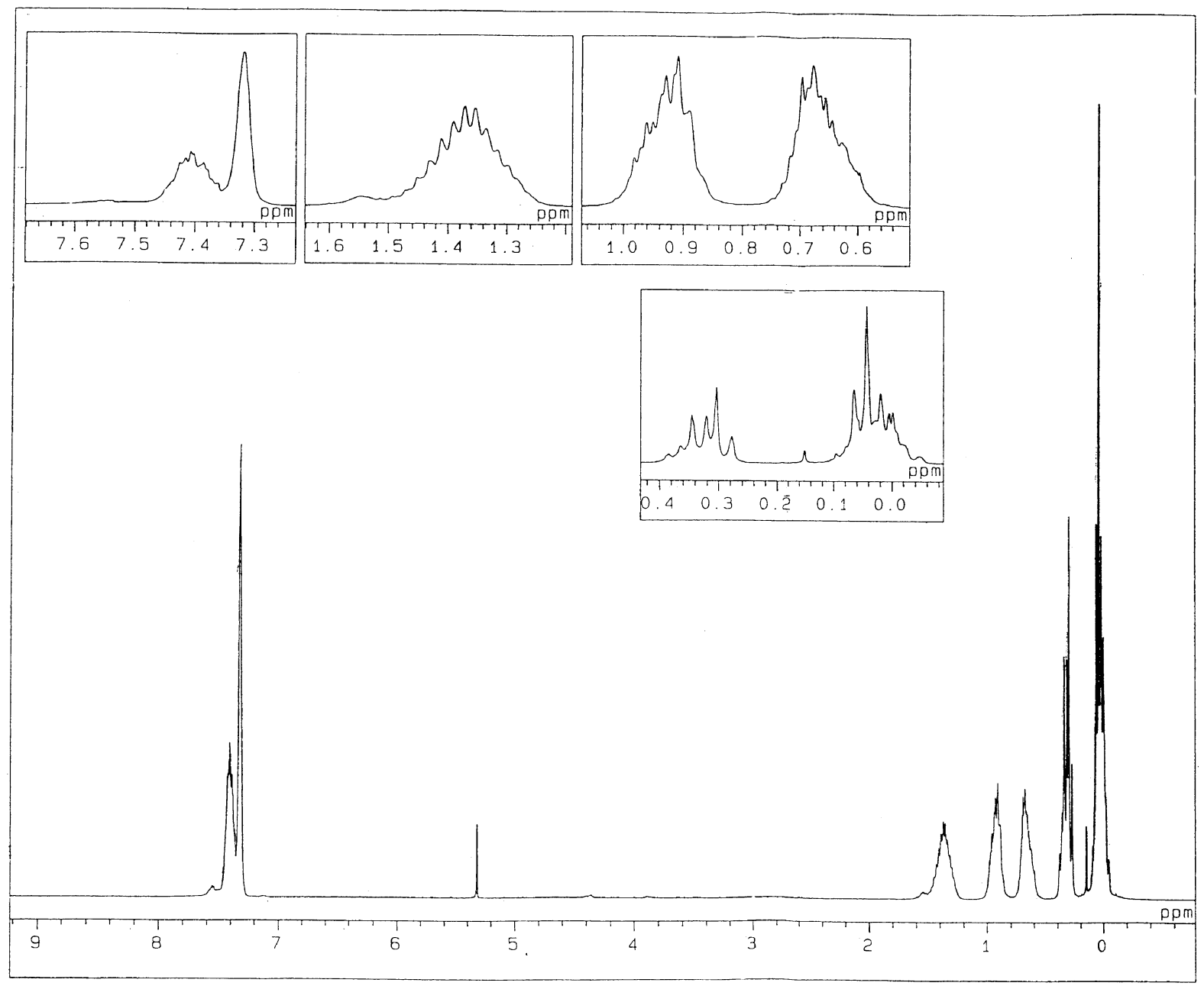

Figure 5. ${ }^{1} \mathrm{H}$ NMR spectrum (in $\mathrm{CD}_{2} \mathrm{Cl}_{2}$ ) of the polymer produced with $\mathrm{Me}_{2} \mathrm{PhSiK}$ (run 4 in Table I).

different from that of the latter reagents. Thus there have been some investigations using cuprate to initiate vinyl polymerization. ${ }^{16}$ Here we made use of silyl cuprate, i.e., $\left(\mathrm{PhMe}_{2} \mathrm{Si}\right)_{2} \mathrm{Cu}(\mathrm{CN}) \mathrm{Li}_{2}$, for the polymerization of $\mathbf{1}$. As was prompted by our preliminary report, ${ }^{17}\left(\mathrm{PhMe}_{2}-\right.$ $\mathrm{Si})_{2} \mathrm{Cu}(\mathrm{CN}) \mathrm{Li}_{2}$ was very recently used as the initiator for the polymerization of cyclotetrasilane. ${ }^{18}$ Table II shows the results of the polymerization of 1 by use of $\left(\mathrm{PhMe}_{2} \mathrm{Si}\right)_{2} \mathrm{Cu}(\mathrm{CN}) \mathrm{Li}_{2}$. The polymerization took place at $0 \sim-78^{\circ} \mathrm{C}$ in THF without HMPA to produce the polymer quantitatively based on the conversion. It should be discussed first that the initiator in run 1 showed very different character from those in other runs. The initiator was freshly prepared just before charging the monomer. The initiator solution prepared at $0^{\circ} \mathrm{C}$ was deep purple while that prepared below $-40^{\circ} \mathrm{C}$ was red. It is known that the THF solution of $\left(\mathrm{PhMe}_{2} \mathrm{Si}\right)_{2} \mathrm{Cu}(\mathrm{CN}) \mathrm{Li}_{2}$ is red, ${ }^{14}$ so that it seems that the initiator prepared at $0^{\circ} \mathrm{C}$ is not actually $\left(\mathrm{PhMe}_{2} \mathrm{Si}\right)_{2} \mathrm{Cu}(\mathrm{CN}) \mathrm{Li}_{2}$. Interestingly, the product polymer in run 1 had a much higher molecular weight and narrower molecular weight distribution than in other runs, though the polymerization took a longer time. This polymerization was, however, poorly reproducible; the molecular weight of the product polymer varied from 18000 to 35000 , and often the polymerization stopped before completion or did not proceed. These observations indicate that a small amount of active
Table II. Anionic ring-opening polymerization of 1,2,2-trimethyl-1-phenyl-1,2-disilacyclopentane (1) initiated with $\left(\mathrm{PhMe}_{2} \mathrm{Si}\right)_{2} \mathrm{Cu}(\mathrm{CN}) \mathrm{Li}_{2}{ }^{a}$ in $\mathrm{THF}$

\begin{tabular}{|c|c|c|c|c|c|c|}
\hline \multirow{2}{*}{ Run } & \multirow{2}{*}{$\frac{\mathrm{Temp}^{\mathrm{b}}}{{ }^{\circ} \mathrm{C}}$} & \multirow{2}{*}{$\frac{\text { Time }}{\mathrm{h}}$} & \multirow{2}{*}{$\frac{\text { Conv. }^{\mathrm{c}}}{\%}$} & \multicolumn{2}{|c|}{$M_{n}$} & \multirow{2}{*}{$M_{w} / M_{n}$} \\
\hline & & & & Obsd $^{\mathrm{d}}$ & Calcd $^{\mathrm{e}}$ & \\
\hline 1 & 0 & 21 & $-f$ & 30000 & - & 1.09 \\
\hline 2 & $0^{\mathrm{g}}$ & 1.1 & 91 & 5800 & 5000 & 1.49 \\
\hline 3 & -40 & 1.0 & 91 & 7000 & 5000 & 1.18 \\
\hline 4 & -50 & 0.3 & 51 & $\begin{array}{c}4200 \\
\left(4000^{\mathrm{h}}\right)\end{array}$ & 2800 & 1.19 \\
\hline 5 & -50 & 1.2 & 88 & $\begin{array}{c}6600 \\
\left(6400^{\mathrm{h}}\right)\end{array}$ & 4800 & 1.21 \\
\hline 6 & -78 & 5.5 & 77 & 5900 & 4200 & 1.18 \\
\hline 7 & -78 & 18 & 94 & 7500 & 5200 & 1.23 \\
\hline
\end{tabular}

a 2 mol\% of $1 .{ }^{b}$ Cuprate was also prepared at this temperature except for run $2 .{ }^{\mathrm{c}}$ Determined by gas chromatography. Polymer yield was quantitative based on the conversion. ${ }^{\mathrm{d}}$ Estimated by GPC (PSt standard, eluent: $\left.\mathrm{CHCl}_{3}\right)$ unless otherwise noted. ${ }^{\mathrm{e}}\{([1] \times$ conv./ $100) /(2 \times$ [cuprate $])\} \times($ MW of $\mathbf{1}) .{ }^{\mathrm{f}}$ Although the conversion was not determined, the polymer yield was $98 \%$. ${ }^{\mathrm{g}}$ Using the cuprate prepared at $-40^{\circ} \mathrm{C}$ (see the text). ${ }^{\mathrm{h}}$ Determined by VPO $\left(\mathrm{CHCl}_{3}, 40^{\circ} \mathrm{C}\right)$.

species, unidentified, was inconstantly generated at $0^{\circ} \mathrm{C}$. On the other hand, run 2, where the monomer was charged to the cuprate prepared at $-40^{\circ} \mathrm{C}$ and the mixture was immediately warmed to $0^{\circ} \mathrm{C}$, gave com- 


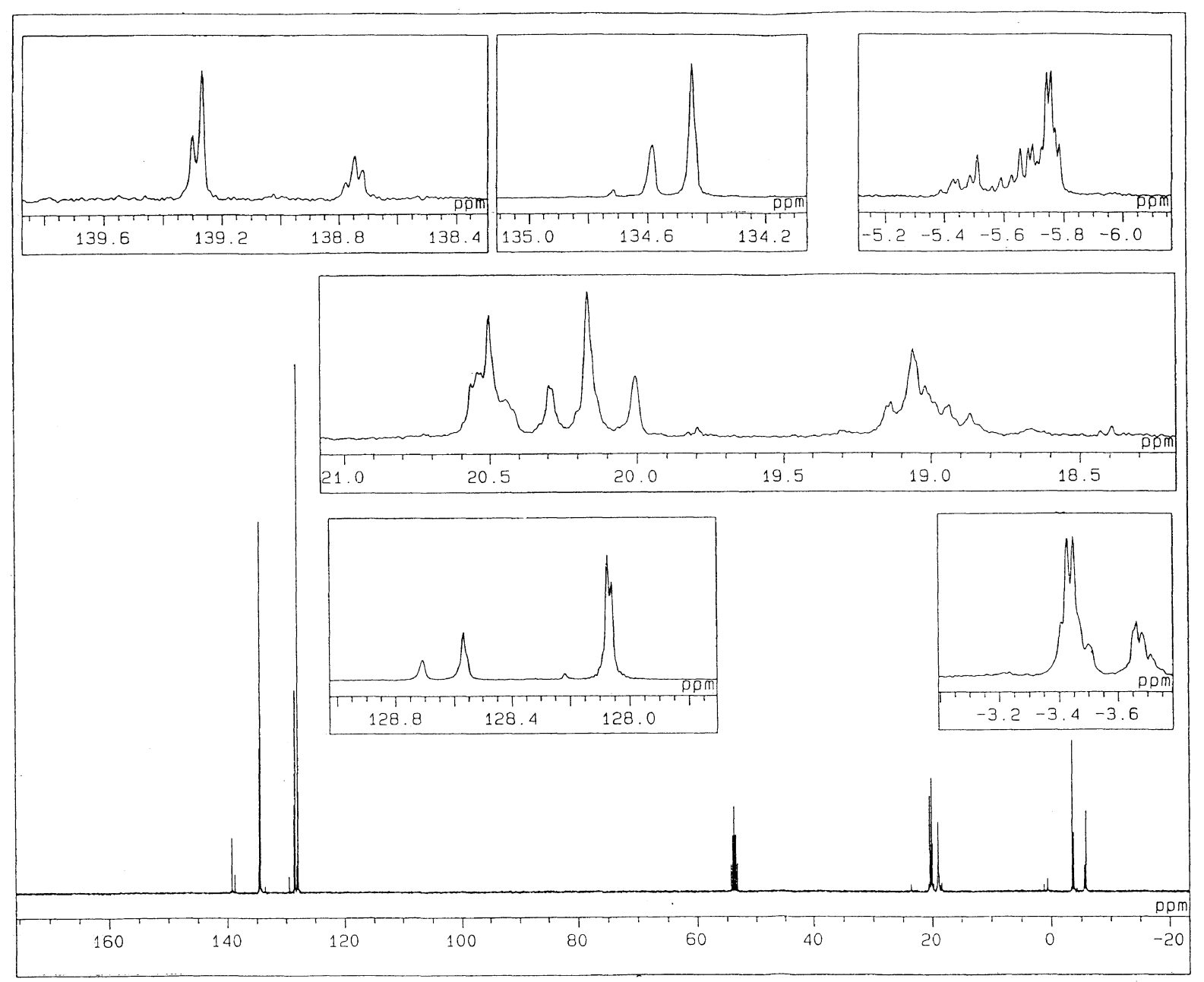

Figure 6. ${ }^{13} \mathrm{C}$ NMR spectrum $\left({ }^{1} \mathrm{H}\right.$ complete decoupling, in $\left.\mathrm{CD}_{2} \mathrm{Cl}_{2}\right)$ of the polymer produced with $\mathrm{Me}_{2} \mathrm{PhSiK}$ (run 4 in Table I).

parable results for runs 3-7. In these runs, the molecular weight of the product polymer almost linearly increased with the conversion of the monomer and was always about 1.4 times the values calculated from the conversion together with the feed ratio of the monomer to the initiator, which is bifunctional. Additionally, the values of the molecular weight distribution were constantly about 1.2. These observations mean that the polymerization has a living character to some extent but the silyl anion added dose not completely work to initiate the polymerization. It is assumed that $\left(\mathrm{PhMe}_{2} \mathrm{Si}\right)_{2}-$ $\mathrm{Cu}(\mathrm{CN}) \mathrm{Li}_{2}$ is not quantitatively formed, as is actually shown in the literature. ${ }^{14}$ In contrast with ${ }^{n} \mathrm{Bu}_{4} \mathrm{NF}$ and $\mathrm{PhMe}_{2} \mathrm{SiK}$, however, $\left(\mathrm{PhMe}_{2} \mathrm{Si}\right)_{2} \mathrm{Cu}(\mathrm{CN}) \mathrm{Li}_{2}$ induced the quantitative conversion of the monomer to the polymer having the narrower molecular weight distribution. These behaviors of the polymerization initiated with $\left(\mathrm{PhMe}_{2} \mathrm{Si}\right)_{2} \mathrm{Cu}(\mathrm{CN}) \mathrm{Li}_{2}$ is owing to the high covalency of an $\mathrm{Si}-\mathrm{Cu}$ bond (electronegativity: $\mathrm{Si}=1.8$ and $\mathrm{Cu}=$ 1.9). The polymerization may propagate via anionic coordination mechanism or one-electron transfer process.

Analysis of the polymer structure by NMR spectroscopy indicated that the polymer contained a small amount of the $\mathrm{H}-\mathrm{H}$ and $\mathrm{T}-\mathrm{T}$ connections. As discussed in the former section, the contents of them were evaluated from the peaks due to the carbon $\mathrm{C}$ in the ${ }^{13} \mathrm{C}$ NMR spectrum: $\mathrm{H}-\mathrm{T}: \mathrm{H}-\mathrm{H}(\mathrm{T}-\mathrm{T})=0.92: 0.04$ (run 1) and $=0.88: 0.06$ (run 5). The high covalency of the $\mathrm{Si}-\mathrm{Cu}$ bond is assumed to reduce the anion stabilization effect of the phenyl group and cause contamination of the $\mathrm{H}-\mathrm{H}$ and $\mathrm{T}-\mathrm{T}$ structures in the product polymer.

Acknowledgments. This research was partly supported by the Grant-in-Aid for Encouragement of Young Scientists (No. 01750841) from the Ministry of Education, Science, and Culture of Japan. M.S. is grateful for this financial support. The authors thank $\mathrm{Mr}$. Haruo Fujita of Kyoto University for measuring the NMR spectra.

\section{REFERENCES AND NOTES}

1. I. Fleming, "Organic Silicon Chemistry," as Part 13 in "Comprehensive Organic Chemistry", D. N. Jones, Ed., Pergamon Press, Oxford, 1979, p 541.

2. a) M. Suzuki, T. Obayashi, and T. Saegusa, J. Chem. Soc., Chem. Commun., 717 (1993). b) M. Suzuki, T. Obayashi, W. Krämer, and T. Saegusa, J. Chem. Soc., Chem. Commun., 553 (1994).

3. M. Suzuki, J. Kotani, S. Gyobu, T. Kaneko, and T. Saegusa, Macromolecules, 27, 2360 (1994).

4. Review: D. Seyferth, ACS Symp. Ser., 360, 21 (1988).

5. a) S. J. Sargeant, S. Q. Zhou, G. Manuel, and W. P. Weber, Macromolecules, 25, 1915 (1992) and references cited therein. b) Review: W. P. Weber, Tr. Polym. Sci., 1, 356 (1993).

6. K. Shiina, J. Organometal. Chem., 310, C57 (1986). 
7. a) K. Matyjazewski, Y. L. Chen, and H. K. Kim, ACS Symp. Ser., 360, 78 (1988). b) M. Cypryk, Y. Gupta, and K. Matyjazewski, J. Am. Chem. Soc., 113, 1046 (1991). c) K. Matyjazewski, M. Cypryk, H. Frey, J. Hrkach, H. K. Kim, M. Moeller, K. Ruehl, and M. White, J. Macromol. Sci. Chem., A28, 1151 (1991)

8. a) K. Sakamoto, K. Obata, H. Hirata, M. Nakajima, and H. Sakurai, J. Am. Chem. Soc., 111, 7641 (1989). b) K. Sakamoto, M. Yoshida, and H. Sakurai, Macromolecules, 23, 4494 (1990). c) K. Sakamoto, M. Yoshida, and H. Sakurai, Polymer, 35, 4990 (1994).

9. a) M. Ishikawa, Y. Hasegawa, T. Hatano, and A. Kunai, Organometallics, 8, 2741 (1989). b) M. Ishikawa, T. Hatano, Y. Hasegawa, T. Horio, A. Kunai, A. Miyai, T. Ishida, T. Tsukihara, T. Yamanaka, T. Koike, and J. Shioya, Organometallics, 11, 1604 (1992). c) M. Ishikawa, T. Horio, T. Hatano, and A. Kunai, Organometallics, 12, 2078 (1993).

10. N. P. Reddy, H. Yamashita, and M. Tanaka, J. Am. Chem. Soc., 114, 6596 (1992)

11. S. O'Brien, M. Fishwick, B. McDermott, M. G. H. Wallbridge, and G. A. Wright, Inorg. Synth., 13, 73 (1971).
12. a) C. Wang, H. Chou, and M. Hung, Hua Hsueh Hsueh Pao, 30 91 (1964) [Chem. Abstr., 61, 1888 (1964)]. b) Z. Zhang and X. Zhou, Huaxue Xuebao, 42, 587 (1984) [Chem. Abstr., 101, 151928 (1984)].

13. E. J. Corey and A. Venkateswarla, J. Am. Chem. Soc., 94, 6190 (1972).

14. a) S. Sharma and A. C. Oehlschlager, Tetrahedron, 45, 557 (1989). b) S. Sharma and A. C. Oehlschlager, J. Org. Chem., 56, 770 (1991).

15. M. Kumada, K. Tamao, T. Takubo, and M. Ishikawa, $J$. Organometal. Chem., 9, 43 (1967).

16. M. Dimonie, D. Mardare, S. Coca, T. E. Hogen-Esch, and J. Zoller, Makromol. Chem., Macromol. Symp., 67, 175 (1993) and references cited therein.

17. a) M. Suzuki, T. Obayashi, Y. Morishima, H. Amii, W. Krämer, and T. Saegusa, Pacific Polym. Prepr., 2, 439 (1991). b) M. Suzuki, T. Obayashi, J. Kotani, Y. Morishima, and T. Saegusa, Polym. Prepr., Jpn., 39, 2014 (1990) [Engl. Ed., 39, E871 (1990)].

18. E. Fossum and K. Matyjaszewski, Macromolecules, 28, 1618 (1995). 